This is a post-peer-review, pre-copyedit version of an article published in Journal of Child and Family Studies. The final authenticated version is available online at: http://dx.doi.org/ 10.1007/s10826-014-9993-5 


\section{Autonomous and Controlled Motivation for Parenting: Associations with Parent and Child Outcomes}

Tomas Jungert, Renee Landry, Mireille Joussemet, Genevieve Mageau, Isabelle Gingras and Richard Koestner

\section{Linköping University Post Print}

\section{Tweet}

N.B.: When citing this work, cite the original article.

The original publication is available at www.springerlink.com:

Tomas Jungert, Renee Landry, Mireille Joussemet, Genevieve Mageau, Isabelle Gingras and Richard Koestner, Autonomous and Controlled Motivation for Parenting: Associations with Parent and Child Outcomes, 2015, Journal of Child and Family Studies, (24), 7, 1932-1942. http://dx.doi.org/10.1007/s10826-014-9993-5

Copyright: Springer Verlag (Germany) http://www.springerlink.com/?MUD=MP

Postprint available at: Linköping University Electronic Press http://urn.kb.se/resolve?urn=urn:nbn:se:liu:diva-119785 


\begin{abstract}
The present investigation examined motivation for parenting and some of its correlates in parents and children. The data came from samples of 151 first-time mothers of infants, 153 mothers of middle school children, and 260 mothers and fathers of high school children. Parents provided self-report data about their motivation in their parenting role as well as reports of role satisfaction, parental competence, child temperament, and parenting styles. Using 3 samples, factor analyses confirmed the distinction between autonomous and controlled forms of parenting motivation. Autonomous motivation refers to investing in the parenting role because it is interesting and meaningful whereas controlled motivation refers to investment based on external or internal pressures. Results showed that autonomous motivation was associated concurrently with parenting satisfaction and competence as well as with authoritative and autonomy-supportive parenting styles. Child temperament was unrelated to parenting motivation, but mothers reported greater autonomous motivation for girls than boys and for younger children rather than older children. Autonomous parenting motivation was associated with children reporting autonomy supportive parenting and high levels of well-being. A prospective analysis showed that controlled parenting motivation in first time mothers was associated with reductions in parenting satisfaction as infants became toddlers. A similar analysis showed that autonomous parenting motivation was associated with children developing fewer behavior problems whereas controlled motivation was associated with children developing more behavioral problems. The present findings highlight the heuristic value of assessing why parents invest themselves in the parenting role.
\end{abstract}

Keywords: motivation for parenting $\bullet$ role satisfaction $\bullet$ parental competence $\bullet$ child temperament $\bullet$ parenting style 
Introduction

Why do people invest themselves in the parenting role? Parents are no doubt motivated by the important role they can play in fostering their children's learning, well-being, and psychosocial adjustment (Joussemet, Landry, \& Koestner, 2008). Yet, parents may be motivated for other reasons, as well. They may be motivated by the interest, challenge, and meaningfulness of the parenting role (termed "autonomous motivation"), but it is also possible others' expectations about how they should act as parents (termed "controlled motivation") are the driving force behind their parenting.

Self-determination theory (SDT; Deci \& Ryan, 2000, 2008) uses the concept of innate, universal, psychological needs to understand human motivation. The theory posits that humans have fundamental needs to feel related, competent, and autonomous in order to develop and function optimally (Deci \& Ryan, 2000). Relatedness refers to feeling connected and cared for by others whereas competence refers to feeling effective and efficacious (Deci \& Ryan, 2000). The core feature of SDT, however, is the emphasis it places on the need for autonomy which refers to the experience of volition in initiating or endorsing behaviors. Stated differently, autonomy means to authentically concur with the internal or external forces that influence behaviors. Autonomy should not be confused with independence or selfishness, rather, autonomy is about volitional, harmonious, and integrated functioning, in contrast to more pressured, conflicted, or alienated experience (Deci \& Ryan, 2000).

Self-determination theory suggests that humans have an innate propensity toward pursuing their intrinsic needs by expressing their interests, seeking to master their environment, and by integrating the values, behaviors, and attitudes of their social surroundings (Ryan, 1995). SDT's organismic assumption of innate integrative tendencies underlying social development (Ryan, 1995) is in line with attachment theories that posit a biologically driven propensity to comply with society’s norms (e.g., Stayton, Hogan, \& Ainsworth, 1971). Importantly, selfdetermination theory also highlights the role of the social context, which can either facilitate or undermine intrinsic and integrative processes. Both intrinsic motivation and internalization are likely to function optimally when children's need for autonomy is supported by parents, teachers, and other socialization agents (Ryan \& Deci, 2000).

Parenting research in the SDT tradition has focused on parents' use of autonomy support to help their children internalize important values and guidelines (Grolnick, Ryan \& Deci, 1991; Pomerantz, Grolnick \& Price, 2005). Autonomy support is defined as encouraging volitional functioning in others by affording opportunities for making choices and initiating actions. For example, studies suggest that parental autonomy support is associated 
Autonomous and Controlled Motivation for Parenting

with internalization (Joussemet, Koestner, Lekes, \& Houlfort, 2004), adjustment at school (Grolnick \& Ryan, 1989; Joussemet, Koestner, Lekes, \& Landry, 2005) and psychosocial functioning (Soenens, Vansteenkiste, et al, 2007). In addition, research has found that autonomy supportive interventions are effective for children (Su and Reeve, 2011) and that parental autonomy support in their children's education predicts positive outcomes (e.g., Froiland 2011). In a qualitative study, Froiland (in press) found that parents experienced that parental autonomy support was associated with children gaining an intrinsic focus and greater enjoyment in many areas.

However, another important question is how the parents themselves internalize expectations, values, and guidelines about how to behave as parents. There are diverse norms about what it means to be a good parent and it seems likely that parents vary greatly in the extent to which they have autonomous versus controlled reasons for pursuing various aspects of the parenting role. Furthermore, the type of motivation toward the parenting role may be importantly related to parenting behavior, parenting adjustment, and child outcomes.

The value of examining parenting motivation can be inferred from a parallel set of studies that have examined teachers' motivation, teacher autonomy support, and student outcomes. Pelletier, Seguin-Levesque, and Legault (2002) conducted a questionnaire study with 254 teachers, from grades 1 to 12 . Four types of teachers' motivation were assessed, including intrinsic motivation, identified regulation, introjected regulation and external regulations. A summary index of self-determination was constructed by combining the intrinsic and identified items and subtracting the extrinsic and introjected items. As expected, teachers' autonomous motivation was associated with autonomy-supportive behavior toward their students.

Another study assessed both teachers and their students to examine the impact of teacher motivation (Roth, Assor, Kanat-Maymon, \& Kaplan, 2007). It was found that autonomous motivation for teaching was associated with autonomy-supportive behavior (as reported by students), which in turn was associated with students' autonomous motivation for learning. Also, autonomous motivation for teaching was positively associated with teachers' sense of personal accomplishment, while it was negatively associated with emotional exhaustion. Together, these studies suggest that, for teachers, autonomous motivation fosters an autonomy-supportive socialization style, which in turn promotes positive outcomes for children. We hypothesize that the same pattern of relations would hold true for parents. That is, parents who possess autonomous motivation for their parenting activities should be more likely to behave in an autonomy supportive manner toward their children. Such an autonomy-supportive parenting style should, in turn, result in positive child outcomes as well as positive outcomes for parents. 
Autonomous and Controlled Motivation for Parenting

The present investigation sought to examine the link between motivation for parenting and parents' behavior and adjustment, as well as the experiences of their children. We developed a scale to assess motivation toward parenting based on methods used to develop scales for motivation in other domains (Ryan \& Connell, 1989). Specifically, items were constructed to assess various reasons for investing in parenting: intrinsic ("I invest myself in parenting because of the pleasure and satisfaction that I experience in taking care of my child"), identified ("because taking good care of my child is important to me and part of my values "), extrinsic ("because I want those around me to see me as a good parent") and introjected ("because I really want to be a good parent and I would be ashamed if I wasn't'). We planned to combine the intrinsic and identified items to form a six-item scale of autonomous motivation and to combine the extrinsic and introjected items to form a six-item scale of controlled motivation. After confirming the psychometric adequacy of our 12-item scale of parenting motivation, we planned to test the relation of autonomous and controlled parenting motivation to a diverse set of parent and child outcomes.

The parenting motivation scale was administered to over 500 parents who were assessed in the context of three different data collection efforts. The first data collection involved first time mothers whose child was between the ages of one and two (Landry, Whipple, et al., 2008). The second data collection involved mothers who had middle school children between the ages of 8 and 14 years old. The final data collection involved mothers and fathers who had high school children between the ages of 12 and 17 (Milyavskaya, Gingras, et al, 2009). All parents completed the parenting motivation scale as well as measures of parenting satisfaction and competence.

Demographic information was also collected. A variety of other scales were completed by subsamples of mothers, including reports of parenting practices and children's temperament.

There were three distinct data sets collected in this investigation: (1) 151 first-time mothers of young infants who were followed up one year later; (2) 153 mothers of middle school children; (3) 260 parents of high school students, whose children also completed scales. We chose not to report the three data collection efforts as Study 1, 2, and 3 because the results are easier to comprehend when organized in terms of the specific research questions.

Study 1 reports a series of analyses of the entire sample of over 500 parents to establish the reliability and basic construct validity of the parenting motivation scales. Specifically, after exploring the factor structure of the autonomy and controlled motivation scales, correlational analyses explored their relation to demographic factors and reports of maternal role satisfaction and perceived competence. Autonomous parenting motivation was expected to 
Autonomous and Controlled Motivation for Parenting

be positively associated with parental satisfaction and competence whereas the opposite was expected for controlled motivation. We did not offer any specific hypotheses regarding the relation of parenting motivation to demographic factors. For the subsample of mothers of infants, the relations of the motivation scales to parenting styles and child temperament measures were explored. We expected that autonomous motivation would be positively associated with authoritative and autonomy supportive parenting styles. We expected controlled parenting motivation to be negatively related to an authoritative parenting style and autonomy-supportive parenting practices. Finally, we hypothesized that children with a difficult temperament might elicit in their mothers controlling parenting motivation rather than autonomous parenting motivation.

Study 2 used data from parents of high school children to explore the relations of parenting motivation to children's well-being and to their perceptions of parental autonomy support. We expected that autonomous parenting motivation would be positively associated with children's reporting that their parents used autonomy supportive parenting methods. We also expected that children of parents who were higher in autonomous parenting motivation would report better mood and higher self esteem.

Study 3 used a prospective longitudinal design to explore the relation of first-time mothers' parenting motivation to their own adjustment and their child's adjustment over the course of one year as their children moved from infancy to toddlerhood. Our guiding hypothesis was that autonomous parenting motivation would be associated with adaptive outcomes for both mothers' and children whereas controlled parenting motivation would not.

\section{Study 1}

We combined the data across our three major data collection efforts in order to explore the factor structure and the basic construct validity of the parenting motivation measure.

Method

Participants

Sample 1. One hundred and fifty-three Canadian first time mothers with children under the age of two participated on a voluntary basis. Thirty-five percent of participants were native English-speakers, $52 \%$ were French-speakers, and $13 \%$ reported another native language. Mean yearly family income was between 50,000 \$ and $75,000 \$ \mathrm{CDN}$, and $63 \%$ of participants reported earning this amount or more. Most of the mothers were university educated (e.g., $49 \%$ completed an undergraduate degree, $18 \%$ completed graduate school). The average age of children was 11.4 months. The data collection of this sample is fully described by Landry et al. (2008). 
Autonomous and Controlled Motivation for Parenting

Of the 162 questionnaires that were sent out, $153(94.4 \%)$ were completed and returned.

Sample 2. The research involved 151 mothers from Montreal (Quebec) with children between the ages of 8 and 16 with a mean of 10.9 years old. The survey asked mothers to report on their motivation for parenting as well as to describe their feelings about being a mother. $67 \%$ of mothers reported English as their native language, $4 \%$ reported French as their native language and $29 \%$ had another native language. Mean yearly family income was between $\$ 30,000$ and $\$ 50,000$ a year and $72.5 \%$ of the participants reported earning this amount or more. Many of the mothers were university educated (e.g., 38.2\% completed an undergraduate degree only, and $19.6 \%$ completed both an undergraduate degree and graduate degree). Of the 163 questionnaires sent out, 151 mothers $(92.6 \%)$ completed and returned them.

Sample 3. We used data collected as part of a cross-cultural study on over-scheduling and school outcomes (Gingras, 2007). Participants were 280 parents (75\% mothers) of students aged 12-18 (mean age 14.5 years old) from Canada, the US, and France. Students were recruited from two high schools in California, USA, two high schools in Quebec, Canada and two high schools in France. We only include the data from cases where both the parent and the child completed the scales. Parental reports were obtained for 97 of 155 French students (63\%), 116 of 248 Canadian students (47\%), and 61 of 161 (38\%) American students.

Procedure

Participants in sample 1 were recruited from the community via newspaper advertisements, flyers, and through social networking among new mothers in Quebec, Canada. Interested mothers who met criteria for the study were sent a questionnaire by mail, along with a $20.00 \$$ gift certificate and were asked to return the questionnaire in the provided stamped and addressed envelope. The questionnaires were originally constructed and written in English, and translated into French by bilingual French-Canadian researchers. Translated versions of the questionnaire were also back-translated to ensure that meaning of each item was conveyed accurately, and discrepancies were resolved through discussion.

Participants in sample 2 were recruited through an ad in the "Montreal Family Magazine". The ad was meant to target both mothers and fathers but almost all of the respondents were mothers. Interested parents were sent a questionnaire by mail. If the parents had more than one child between the ages 8 and 16, they were told to report on the child closest to age 12 . Once the questionnaire was completed and returned (along with the consent form) in 
Autonomous and Controlled Motivation for Parenting

the stamped and addressed envelope provided, participants were sent a $20.00 \$$ gift certificate of a popular book store. The instruments included in the questionnaire were constructed and written in English.

In sample 3, students completed questionnaires during an allotted time during the school day in each school, with permission from the principals. Parents were also asked to complete a short questionnaire; no compensation was offered in this study. Measure Completed by Mothers in All Studies.

Parenting motivation. An adapted version of the Self-Regulation Questionnaire (Ryan \& Connell, 1989) was used to assess motivation toward parenting. Parents were asked why they invested time and energy in the task of child rearing. The stem used was "I am motivated to take care of my child because..." Twelve items, three for each type of motivational style, were rated on a 7-point scale, from "strongly disagree" to "strongly agree." Items included "because of the pleasure and satisfaction that I experience in taking care of my child" (intrinsic motivation); "because taking good care of my child is important to me" (identified motivation); "because if I wasn't a good parent, I would feel guilty" (introjected regulation); "because I want those around me to see me as a good parent" (extrinsic regulation). Subscales for autonomous motivation (intrinsic and identified motivation) and controlled motivation (introjected and external regulation) were created by calculating the mean of six items. Table 2 provides all of the items. The scale does not assess the extent to which parents actually invest time and energy, rather, it examines why parents believe they are investing time and energy into their role as parents.

Perceived Parental Competence and Parental Satisfaction. Perceived parental competence and parental satisfaction were assessed with a modified version of the Self-Perceptions of the Parental Role instrument (SPPR; MacPhee, Benson, \& Bullok, 1986). The original SPPR is a 22-item measure consisting of four scales that assess different aspects of the parental role: Competence, Satisfaction, Investment, and Role Balance. Each item is made up of a pair of statements that describe contrasting endpoints of a parenting dimension. Twelve items from the competence and satisfaction subscales were used, six items from each scale. Items were modified for the purpose of clarity, such that instead of choosing one side or the other (e.g., "being a parent is a satisfying experience for me" versus "being a parent is not at all satisfying for me") participants were asked to rate the extent to which they agreed with only one side of the statement. In addition, the items were personalized (e.g., instead of "some parents feel," the modified version used "I feel"). An example of a competence item is "I feel that I am doing a good job of providing 
Autonomous and Controlled Motivation for Parenting

for my child's needs." The questions were answered on a 7-point scale ranging from disagree to agree. The reliabilities for the competence and satisfaction scales were adequate, alphas $>.75$.

Demographic information. Participants were asked to indicate their child's gender and their own age, ethnicity, level of education completed, and approximate yearly family income.

Measures Completed by Subsamples of Mothers.

Temperament of child. This construct was assessed in the data collection of mothers of infants. A shortened version of the Infant Characteristic Questionnaire (ICQ; Bates, Freeland, \& Lounsbury, 1979) was used to assess parents' perceptions of their child's “difficult temperament." Seven items assessing fussiness that were applicable to different-aged children were used in the current study. Sample items included: "how much does your baby cry and fuss in general?" and "what kind of mood is your baby generally in?" Ratings were made on a 7-point scale ranging from "not at all" to "a great deal." Internal consistency for the Fussy-Difficult subscale was .79 in the original study (Bates et al., 1979) and it was .78 in this study.

Maternal permissiveness and authoritativeness. A modified version of the Parenting Practices

Questionnaire (Robinson et al. 1995), which is based on Baumrind's (1971) authoritative, authoritarian, and permissive typology was used to assess parental permissiveness and authoritativeness. The PPQ is a 62 -item parent self-report measure that was originally developed to assess parenting styles among parents of preadolescent children. However, only items that seemed appropriate for very young children were used in the current study. Eight items from the permissive subscale were used. Each item was rated on a scale from 1 (never) to 5 (always). Sample items include: "I spoil my child", and "I find it difficult to set limits with my child”. Eight items were also used from the authoritative parenting scale. Sample items include "I give praise when my child is good," and "I convey my expectations regarding behavior to my child before s/he engages in an activity." The two scales had only modest reliability, alphas $=.61$ and .60 , and they were uncorrelated, $\mathrm{r}=-.10$.

Satisfaction With Life Scale (SWLS). The SWLS is a five-item scale that assesses global life satisfaction (Diener, Emmons, Larsen, \& Griffin, 1985). Participants rated items such as "the conditions of my life are excellent" on a 7-point scale of agreement. Reliability and validity of the SWLS are described by Diener, et al. (1985). The internal reliability in this study was alpha $=.87$.

Mood valence. A nine-item affect scale was used (Emmons, 1992). Participants were asked to rate each item, based on how they felt that during the past week, using a scale of 1 to 5 , with 1 representing very slightly and 5 
representing extremely. The items were: joyful, unhappy, worried/anxious, enjoyment/fun, depressed, pleased, happy, angry/hostile, and frustrated. Negative affect items were reversed and combined with the positive items. These scales have excellent temporal reliability and internal consistency (Diener \& Emmons, 1984). In the present study the reliability was alpha $=.83$.

\section{Results}

Preliminary Analyses

The 12 parenting motivation items were subjected to a principal components analysis with Varimax rotation. Two factors accounted for $51.72 \%$ of the variance. The first factor had an Eigen value of 3.96 and the second had a value of 2.25. Table 1 shows the factor loadings for all items. It can be seen that the extrinsic and introjected items loaded on the first factor which appears to reflect controlled motivation, whereas the intrinsic and identified items loaded on the second factor which appears to reflect autonomous motivation. The six autonomous motivation items yielded an internal reliability of .78 whereas the six controlled motivation items yielded a reliability of .82. Autonomous and controlled parenting motivation scores were calculated as the mean of the six items loading on their respective factor. The two scales were moderately positively correlated, $\mathrm{r}=.27, \mathrm{p}<.01$.

The second data collection included fathers as well as mothers. T-tests were used to examine differences in parenting motivation between mothers and fathers. No significant differences were obtained: $t(266)=1.49$ for autonomous motivation and $\mathrm{t}(266)=-1.16$ for controlled motivation. The means were as follows: autonomous motivation, Mothers' $M=6.17$, Fathers' $M=6.04$; controlled motivation, Mothers' $M=4.25$, Fathers' $M=4.46$.

The second data collection also included parents from three countries. A one-way analysis of variance revealed significant differences in reports of parenting motivation across the three countries: Autonomous motivation, $\mathrm{F}(2,265)=7.66, \mathrm{p}<.001$; Controlled motivation, $\mathrm{F}(2,265)=4.25, \mathrm{p}<.05$. French parents reported lower levels of autonomous motivation $(M=5.96)$ than Americans $(M=6.33)$ and Canadians $(M=6.20)$. They also reported higher levels of controlled motivation $(M=4.59)$ than Americans $(M=4.26)$ and Canadians $(M=4.07)$.

Insert Table 1 About Here 


\section{Central Analyses}

Table 2 presents the partial correlations of autonomous parenting motivation and controlled parenting motivation with all of the other measures collected from mothers, except those in the prospective study. Partial correlations were used because of the significant positive relation between autonomous and controlled parenting motivation. It can be seen that autonomous parenting motivation was significantly positively associated with parent role satisfaction and parental competence, as well as with general life satisfaction and positive mood. Autonomous motivation was also significantly positively associated with authoritative and autonomy supportive parenting styles. Unexpectedly, autonomous motivation was higher for parents of girls than boys, and for parents with younger children. Autonomous parenting motivation was unassociated with education, income, child temperament, permissive parenting practices, and social desirability.

Insert Table 2 About Here

Controlled parenting motivation was significantly negatively associated with parental competence, parental role satisfaction, general life satisfaction, and positive mood. No other correlations were significant for controlled motivation.

\section{Discussion}

This study explored the factor structure of the parenting motivation scale and its relation to different parent and child variables. The factor solution revealed two distinct factors reflecting controlled parenting motivation and autonomous parenting motivation. Surprisingly, these two dimensions of parenting motivation were moderately positively related to each other, necessitating the use of partial correlation analyses to explore their correlates. While autonomous motivation was associated with higher self-ratings of parental competence, role satisfaction, higher positive mood and life satisfaction, controlled motivation was negatively related to these well-being indicators. Autonomous motivation was also positively related to an optimal parenting style (authoritative; autonomysupportive). This pattern of correlations conformed to our hypotheses. 
Study 2

The results reported in Study 1 provide initial support for the reliability and validity of the parenting motivation scales. Our next study aimed to strengthen the construct validity of the parenting motivation measure by examining the relation of autonomous and controlled parenting motivation to their parenting, as perceived by their adolescents, as well as to youth' well-being. Specifically, we were able to examine the relations of parenting motivation to child reports of self-esteem, positive mood, and their perceptions of the extent to which their parents adopt an autonomy supportive parenting style toward them.

\section{Child measures}

Child demographic characteristics. The sample of youth participants who completed the scales had the following demographic characteristics: $43 \%$ were Canadian, 35\% French, and 22\% American. The respondents were predominantly female $(57 \%)$ and their mean age was 14.5 .

Perceptions of Autonomy-Support. The Perception of Autonomy Support Scale (Robbins 1994), a 9-item scale, was used to measure the degree to which adolescents report that their autonomy is supported by their parents. Participant rate on a scale of 1 (not at all true) to 5 (very much true) the extent to which each statement applies to them. For example, "my parents listen to my opinion or perspective when I've got a problem," and "my parents aren't very sensitive to my needs (reverse item)". To obtain the overall score, a mean of the 9 items is calculated, and a higher score indicates a greater perception that the child's autonomy is supported by the parent. The internal reliability was quite high, alpha $=.85$.

Child Well-Being. Well-being was measured through positive and negative affect as well as self-concept. On the Positive and Negative Affect Scale (Emmons 1992), respondents indicated the extent to which they felt a series of emotions over the past 4 days: four positive feelings (joyful, enjoyment/fun, pleased, happy) and six negative feelings (unhappy, worried/ anxious, depressed, angry/hostile, frustrated, stressed) from 1 (slightly or not at all) to 5 (extremely).Positive affect and negative affect were highly negatively related, $r=-.36$. An index of affect used in the analyses was calculated by reversing negative affect and combining it with positive affect.

Using Anderman's (2002) self-esteem scale, respondents rated the extent to which they agreed or disagreed with six statements about themselves (e.g., "I have a lot to be proud of').Statements were rated on a five-point 
Autonomous and Controlled Motivation for Parenting

scale ranging from 1 (strongly disagree) to 5 (strongly agree). To obtain a global score, the mean of the six items was calculated. An acceptable internal reliabilities of alpha $=.75$ was obtained.

A global index of child well-being was calculated as the mean of the standardized score for positive and negative affect valence and self-esteem. The creation of a global index was used because of the high positive correlation between affect and self-esteem $(r=.47)$, and because our predictions were framed in terms of general well-being. The reliability for the global index (using all mood and self-esteem items) was alpha $=.83$.

\section{Results}

To examine the relation of parenting motivation to child reports, two hierarchical linear regression analyses was conducted with perceived autonomy support and child adjustment as the dependent variables. The first set of predictors included parent's gender, child's gender, parent's age, education level, and country. The latter two variables were entered as two dummy codes. Autonomous and controlled parenting motivations were entered next. Finally, all of the two-way interactions between the demographic variables and the two parenting motivations were entered as a third set of variables.

The regression of children's perceived autonomy support yielded a significant multiple R of .39, F (16,249) $=2.71, \mathrm{p}<.001$. The only demographic variable found to relate to autonomy support was children's age $(\beta=.14, \mathrm{p}$ $<.05)$. Older children reported higher levels of parental autonomy support. Both parenting motivation variables were significantly associated with perceived autonomy support. Autonomous motivation was significantly positively related to autonomy support, beta $=.23, \mathrm{t}(257)=3.60, \mathrm{p}<.001$ whereas controlled motivation was significantly negatively related to perceived autonomy support, beta $=-.14, \mathrm{t}(257)=2.24, \mathrm{p}<.05$. Two interaction terms were also significant. An interaction between parent's gender and autonomous motivation $($ beta $=.17, \mathrm{t}(249)=2.72, \mathrm{p}<$ $.01)$ reflected the fact that fathers' autonomous motivation was especially strongly related to children's perceived autonomy support. In addition, an interaction between one of the dummy codes for country and controlled motivation $($ beta $=.17, \mathrm{t}(249)=2.17, \mathrm{p}<.01)$ reflected the fact that controlled motivation was negatively related to perceived autonomy support among Canadian and French families (betas $=-.21$ and -.26 , respectively) but it was positively related to perceived autonomy support among American families (beta $=.21$ ). No other interactions approached significance. 
Autonomous and Controlled Motivation for Parenting

The regression of children's well being yielded a non-significant multiple R of .28, F $(16,249)=1.32$, n.s. The only significant predictor to emerge in this regression was parent's level of autonomous motivation: beta $=.14$, $\mathrm{t}(257)=2.09, \mathrm{p}<.05$. Children whose parents were higher in autonomous motivation reported greater well being. None of the interactions approached significance (p's $>.20)$.

\section{Discussion}

The results of study 2 provided further support for the usefulness of the measure of autonomous parenting motivation. Study 2 overcame the problem of shared method variance by assessing child variables from a separate source than parenting motivation. Importantly, we were able to confirm significant relations between parenting motivation and perceived autonomy support from children. The results also indicated that autonomous motivation

was associated with better child well-being. Despite this methodological improvement, it is still impossible to certify the direction of causality in the relation of parents' autonomous parenting motivation to their parenting and adolescents' well-being.

\section{Study 3}

Study 3 used a 1-year prospective design to examine the association between parenting motivation in firsttime mothers and maternal and child adaptation over time, controlling for initial levels of adaptation and child temperament.

\section{Method}

\section{Participants}

First-time mothers who had participated in the first data collection were followed approximately one year later, when their child was a toddler. Of the 153 mothers who were sent questionnaires, 116 returned them, for a response rate of $76 \%$. Eleven of the envelopes were returned by the postal service because of a change of address. Of these 116 participants, 48\% were French-speakers, 37\% were native English-speakers, and 15\% reported another native language. Mean age of mothers at Time 2 was 31.5 years, and mean age of their toddler was 23 months. Sixty percent of the toddlers were boys, and $40 \%$ were girls. Ninety-four percent of the mothers reported that they were living with their child's father. Mean yearly family income was between $\$ 50,000$ and $\$ 75,000 \mathrm{CAD}$, and $70 \%$ of participants reported that their family income was in this range or higher. Most of the mothers were university educated (e.g., $48 \%$ completed an undergraduate degree, $20 \%$ completed graduate school). 
Autonomous and Controlled Motivation for Parenting

Procedure

Mothers who had participated in Study 1 were sent a questionnaire by mail when their child had reached (at least) 18 months. Participants were asked to return the questionnaire in the stamped and addressed envelope provided. Participants were sent a $\$ 15.00 \mathrm{CAD}$ gift certificate at a popular bookstore after retuning their completed questionnaire.

Measures

Perceived Parental Competence and Parental Satisfaction. The same scales that were administered in study 1 were used, with 6 items assessing competence and 6 items assessing satisfaction. The reliabilities, were adequate, alphas $>.76$.

Child behavior problems. The Child Behavior Checklist for ages 1 - 5 (Achenbach 2000; Achenbach \& Rescorla, 2000) measures diverse aspects of a child's behavioral, emotional, and social functioning. The CBCL/1-5 was designed to be completed by parents or parent surrogates.

The respondent is asked to rate 99 problem items as 0 for not true of the child, 1 for somewhat or sometimes true, and 2 for very true or often true, based on the preceding 2 months. A child's behavior problem score was obtained by averaging the scores on each of the 99 items, with high scores reflecting more problems related to the child's behavioral, emotional, and social functioning.

Results

To examine the relation between parenting motivation and adjustment outcomes over time, a series of hierarchical linear regression analyses were conducted with maternal perceived competence and role satisfaction as the dependent variables. Participants' level of education and income were entered together with child's temperament and participants' Time 1 score on either competence or satisfaction as a first set of predictors. Time 1 parenting motivation (autonomous and controlled) was entered second.

The regression of role satisfaction yielded a significant multiple $\mathrm{R}$ of $.48, \mathrm{~F}(6,109)=5.46, \mathrm{p}<.001$. Initial maternal role satisfaction was significantly positively related to later maternal satisfaction $($ beta $=.40, \mathrm{t}(111)=4.42$, $\mathrm{p}<.001$. Controlled parenting motivation at Time 1 was significantly negatively associated with maternal role satisfaction adjustment at Time 2 (beta $=-.26, \mathrm{t}(109)=-2.83, \mathrm{p}<.01)$. Autonomous motivation was unrelated to later role satisfaction $($ beta $=.12, \mathrm{t}(109)=1.21, \mathrm{p}=.23)$. No other effects approached significance in this regression $($ p’s $>10)$. 
Autonomous and Controlled Motivation for Parenting

The regression on perceived competence revealed no effects for either autonomous $($ beta $=.05)$ or controlled parenting motivation (-.09).

To examine the relation between parenting motivation and later child behavior problems, a hierarchical linear regression analysis was conducted with child behavior problems at Time 2 as the dependent variable. The first set of predictors was level of education, family income, and child's temperament. Autonomous motivation and controlled motivation were entered second. The regression yielded a significant multiple $\mathrm{R}$ of $.47, \mathrm{~F}(8,110)=6.10$, $\mathrm{P}$ $<.001$. Difficult temperament at Time 1 was significantly positively associated with behavioral problems at Time $2($ beta $=.30, \mathrm{t}(112)=3.26, \mathrm{p}<.001)$. Autonomous parenting motivation at Time 1 was significantly positively related to fewer behavior problems at time 2 , (beta $=-.19, \mathrm{t}(110)=-2.02, \mathrm{p}<.05)$. By contrast, controlled parenting motivation was significantly positively related to later child behavior problems $($ beta $=.32, \mathrm{t}(110)=3.53$, $\mathrm{p}<.001)$. No other effects approached significance in this regression, $\mathrm{p}$ 's $>.10$ ).

\section{Discussion}

The results of Study 3 demonstrated that controlled motivation for parenting placed first-time mothers at risk for adjustment difficulties during the transition from infancy into toddlerhood. Surprisingly, autonomous motivation was unrelated to later parent role satisfaction. Autonomous and controlled parenting motivations were both significantly related to child adjustment over time, in opposite directions. As expected, autonomous motivation was associated with a positive adjustment for young children whereas controlled motivation was associated with behavioral and emotional problems.

\section{General Discussion}

The present investigation was designed to explore the idea that autonomous motivation for parenting is associated with successful adaptation in parents and their children. Autonomous motivation has been measured in many different domains and it has consistently been linked with positive adjustment (Deci \& Ryan, 2008). Although self-determination theory researchers have explored issues related to autonomy in parenting, this work has almost exclusively focused on whether parents behave toward their children in autonomy-supportive ways. No previous research, to the best of our knowledge, has explored whether parents differ in their level of autonomous motivation to participate in various parenting activities, and whether such motivational differences will be associated with 
Autonomous and Controlled Motivation for Parenting

different qualitative outcomes for parents and children. In the present investigations, we developed a motivation for parenting scale that was modeled after previous scales in other domains (cf., Ryan \& Connell, 1989).

The present studies examined the relations of levels of autonomous and controlled motivation for parenting to different parent and child factors. Study 1 looked at the link between motivation for parenting and a variety of parental and demographic variables. Study 2 examined the relations between mothers' and fathers' motivation for parenting and their high school children's self-reports of self-esteem, positive mood and the perceived autonomysupport from their parents. Study 3 used a 1-year prospective design to examine whether motivation for parenting would be associated with better maternal and child outcomes over time, measured by mothers' competence and satisfaction, and low child behavioural problems. Our general prediction was that autonomous motivation for parenting would be significantly positively associated with better adjustment for both the parents and the children, whereas controlled motivation would be either negatively related or unrelated.

The present investigation included three separate attempts to examine the links between parenting motivation and parenting style. In a sample of first-time mothers, it was shown that autonomous motivation was significantly positively associated with authoritative parenting but unrelated to permissive parenting. In a sample of mothers of middle school children, autonomous motivation was significantly associated with mother's reports of behaving toward their children in an autonomy supportive manner. The measure used in this study was taken directly from the self-determination theory literature. Most impressively, in a study of 260 parents and high school students from three countries, it was shown that autonomous parenting motivation was significantly positively associated with children's perceptions that their parents behaved in autonomy supportive ways, whereas there was a significant negative association for controlled motivation with such perception. Together, these findings seem to point to a reliable association between motivation and parenting style among parents.

Overall the results support our hypothesis that parents who are more autonomously motivated in their parenting roles are also those who report positive outcomes. Study 1 showed that autonomous motivation was associated with higher self-ratings of parental competence and satisfaction, as well as reports of more positive mood and higher life satisfaction. Controlled motivation was negatively related to concurrent reports of satisfaction and competence. However, study 3 showed that among first-time mothers it was controlled motivation, not autonomous motivation, which was significantly predictive of decreases in mothers' feelings of role satisfaction as their children progressed from infants to toddlers. Controlled motivation was also predictive of these children displaying 
significantly higher levels of behavioural problems over time whereas autonomous motivation was associated with fewer problems over time. Together, these results provide initial support for the hypothesis that motivation for parenting will be associated with higher levels of adjustment in both parents and children.

The results contribute to SDT in that we found similar associations between a parent's autonomous motivation and outcomes and between parent and child as have previously been found in the autonomous motivation of teachers and other outcomes and between teacher and student. Just as students feel more autonomous when their teacher is autonomously motivated, parents' autonomous motivation was associated with their children's perceptions of them as autonomy-supportive towards them.

The results showed no relationship between parenting motivation and levels of family income or education. Parenting motivation also did not seem to differ between mothers and fathers, but our investigation included only a small sample of fathers. Parent's age was unrelated to motivation. There was a significant relationship between autonomous motivation for parenting and the age of the child; mothers of younger children reported more autonomous motivation for parenting than parents of older children. The difficulty many parents experience when their children move from childhood to adolescence may explain part of the difference that we see in their autonomous motivation. One can imagine parents becoming less intrinsically motivated and identified with their role as their teenagers strive for separation and orient toward their peers. There was also an unexpected association between child gender and parenting motivation. Parents reported significantly greater autonomous motivation for investing themselves in parenting a girl than for a boy. Because we did not include many fathers in our studies we cannot sort out whether this result reflects a motivational advantage for parenting a same-gendered child. We would speculate that this result may relate to the fact that boys typically show higher levels of externalizing problems than girls, and thus they may, on average, pose a challenge to maintaining intrinsic and identified reasons for investing in one's parent role.

Although this study is an interesting first step towards examining motivation for parenting, it has many limitations. First, the majority of participants were mothers and although mothers are still the main caretakers in society, fathers are becoming more and more involved in their children's upbringing. It is important to include equal numbers of fathers in subsequent studies on motivation for parenting. Indeed, examining the match between mothers and father's motivational orientation would be very interesting, as would the examination of non-traditional forms of parenting unions. 
Autonomous and Controlled Motivation for Parenting

Second, although the present investigation tried to get beyond the problems of shared method variance by including child reports in study 2 , it is important for future research on parenting motivation to gather more diverse and compelling evidence of predictive validity. For example, peer reports could be used to confirm the adjustment advantages that seem to be associated with autonomous parenting motivation, and systematic behavioral observations could be used to determine whether parenting motivation is directly associated with observed behavior toward children.

A final problem with our research is that we did not fully demonstrate linkages between parenting motivation, parental autonomy support, and children behaving in autonomous ways. Children whose autonomy is supported by their parents internalize guidelines more fully, are better adjusted, and perceive themselves as more competent (Deci \& Ryan, 1991; Grolnick and Ryan, 1989). Roth and colleagues (2007) showed that teachers' autonomous motivation was directly tied to their use of autonomy support and, in turn, their students' reports of autonomous motivation at school. Our research should have also assessed these three different standpoints on autonomy.

Although our research included participants from Canada, the United States, and France, it was not designed to systematically examine the relation of cultural factors to parenting motivation. Such an investigation would have required consistent sampling from more diverse cultures (e.g., include South Asian and South American families) across all of our studies while also including measures of culture-related values and standards. It would be interesting to determine whether cultural variations in collectivistic versus individualistic values, or in hierarchical versus egalitarian values would be associated with parenting motivation.

In support of research in other domains, our studies showed that the distinction between autonomous and controlled parenting motivations is important. Our results suggest that autonomous and controlled motivation are significantly associated with a distinct set of parent and child outcomes. But what factors influence whether parents develop primarily autonomous or controlled reasons for their parenting? We would hypothesize that parents' childhood experiences with their own parents may influence the kind of motivations they adopt toward parenting. Also, we expect that the availability of interpersonal supports for parenting (e.g., living near to one's extended family, a flexible work environment, and a network of helpful friends) would conduce toward parents being able to focus on the ways in which parenting can be interesting and meaningful rather than on the pressures of the role. 


\section{References}

Achenbach, T. M. (2000). Child behavior checklist. In A. E. Kazdin (Ed.), Encyclopedia of psychology (Vol. 2, pp. 69-70). Washington, DC: Oxford University Press.

Achenbach, T. M., \& Rescorla, L. A. (2000). Manual for the ASEBA preschool forms \& profiles. Burlington, VT: University of Vermont, Research Center for Children, Youth, \& Families.

Anderman, E. M. (2002). School effects on psychological outcomes during adolescence. Journal of educational psychology. 94(4), 795-809.

Bates, J. E., Freeland, C. A., \& Lounsbury, M. L. (1979). Measurement of infant difficultness. Child Development, 50, 794-803.

Baumrind, D. (1971). Current patterns of parental authority. Developmental Psychology, 4, 1-103.

Deci, E. L., \& Ryan, R. M. (1985). The general causality orientations scale: Self-determination in personality. Journal of Research in Personality, 19, 109-134.

Deci, E. L., \& Ryan, R. M. (2000). The "what" and "why” of goal pursuits: Human needs and the self-determination of behavior. Psychological Inquiry, 11, 227-268.

Deci, E. L., \& Ryan, R. M. (2008). Self-determination theory: A macro theory of human motivation, development, and health. Canadian Psychology, 49, 182-185.

Diener, E., Emmons, R. A., Larsen, R. J., \& Griffin, S. (1985). The life with satisfaction scale. Journal of Personality Assessment, 49, 71-76.

Emmons, R. A. (1992). Abstract versus concrete goals: Personal striving level, physical illness, and psychological well-being. Journal of Personality and Social Psychology, 62(2), 292-300.

Froiland, J. M. (2011). Parental autonomy support and student learning goals: A preliminary examination of an intrinsic motivation intervention. Child \& Youth Care Forum, 40, 135-149.

Froiland, J. M. (in press). Parents' weekly descriptions of autonomy supportive communication: Promoting children's motivation to learn and positive emotions. Journal of Child and Family Studies.

Gingras, I. (2007). S'impliquer dans l'éducation des enfants, mais pas trop non plus: la balance clé pour le bien-être des enfants. Final research report presented to the Fonds québécois de la recherche sur la société et la culture (FQRSC). 
Grolnick, W. S. (2003). The psychology of parental control: How well-meant parenting backfires. Mahwah, NJ, US: Lawrence Erlbaum Associates Publishers.

Grolnick, W. S., Ryan, R. M., \& Deci, E. L. (1991). Inner resources for school achievement: Motivational mediators of children's perceptions of their parents. Journal of Educational Psychology, 83, 508-517.

Grolnick, W. S., \& Ryan, R. M. (1989). Parent styles associated with children's self-regulation and competence in school. Journal of Educational Psychology 81, 143-154.

Joussemet, M., Koestner, R., Lekes, N., \& Landry, R.(2005) A longitudinal study of the relations maternal support to children's adjustment and achievement in school. Journal of Personality, 73, 1215-1235.

Joussemet, M., Koestner, R., Lekes, N., \& Houlfort, N. (2004). Introducing uninteresting tasks to children: A comparison of the effects of rewards and autonomy support. Journal of Personality, 72, 141-169

Joussemet, M., Landry, R., \& Koestner, R. (2008). A self-determination theory perspective on parenting. Canadian Psychology, 49, 194-200.

Kins, E., Beyers, W., Soenens, B., \& Vansteenkiste, M. (2009). Patterns of home leaving and subjective well-being in emerging adulthood: The role of motivational processes and parental autonomy support. Developmental Psychology 45, 1416-1429.

Koestner, R., Ryan, R. M., Bernieri, F., \& Holt, K. (1984). Setting limits on children's behavior: The differential effects of controlling vs. informational styles on intrinsic motivation and creativity. Journal of Personality, $52,233-248$.

Landry, R., Whipple, N., Mageau, G., Joussemet, M., Koestner, R., DiDio, L., Gingras, I., Bernier, A., \& Haga, S. M. (2008). Trust in organismic development, autonomy support, and adaptation among mothers and their children. Motivation and Emotion, 32, 173-188.

LeCroy, C. W. (1988). Parent-adolescent intimacy: Impact on adolescent functioning. Adolescence, 23, $137-147$.

MacPhee, D., Benson, J. B., \& Bullock, D. (1986). Influences on maternal self-perceptions. Paper presented at the Fifth Biennial International Conference on Infant Studies.

Milyavskaya, M., Gingras, I., Mageau, G., Koestner, R., Gagnon, H., Fang, J., \& Boiche, J. (2009). Balance across contexts: The importance of balanced need satisfaction across life domains in adolescence. Personality \& Social Psychology Bulletin.35, 1031-1045. 
Pelletier, L. G., Séguin-Lévesque, C., \& Legault, L. (2002). Pressure from above and pressure from below as determinants of teachers' motivation and teaching behaviors. Journal of Educational Psychology, 94, 186196.

Pomerantz, E. M., Grolnick, W. S., \& Price, C. E. (2005). The role of parents in how children approach achievement: A dynamic process perspective. In A. J. Elliot \& C. S. Dweck (Eds.), Handbook of competence and motivation (pp. 229 -278). New York: Guilford Press Publications.

Roth, G., Assor, A., Kanat-Maymon, Y., \& Kaplan, H. (2007). Autonomous motivation for teaching: How selfdetermined teaching may lead to self-determined learning. Journal of Educational Psychology, 99(4), 761774.

Robinson, C. C., Mandleco, B., Olsen, S. F., \& Hart, C. H. (2001). The parenting styles and dimensions questionnaire. In J. Touliatos \& B. Perlmutter (Eds.), Handbook of family measurement techniques, (2nd ed., pp. 319-321). Thousand Oaks: Sage.

Ryan, R. M. (1995). Psychological needs and the facilitation of integrative processes. Journal of Personality, 63, $397-427$.

Ryan, R. M., \& Connel, J. P. (1989). Perceive d locus of causality and internalization: Examining reasons for acting in two domains. Journal of Personality and Social Psychology, 57(5), 749-761.

Ryan, R. M., \& Deci, E. L. (2000). The darker and brighter sides of human existence: Basic psychological needs as a unifying concept. Psychological Inquiry, 11, 319-338.

Ryan, R. M., Deci, E. L., Grolnick, W. S., \& La Guardia, J. G. (2006). The significance of autonomy and autonomy support in psychological development and psychopathology. In D. Cicchetti \& D. J. Cohen (Eds.), Developmental psychopathology (2nd ed., Vol. 1). Hoboken, NJ: Wiley.

Soenens, B., Vansteenkiste, M., Lens, W., Luyckx, K., Goossens, L., Beyers, W., Ryan, R. M. (2007).

Conceptualizing parental autonomy support: Adolescent perceptions of promotion of independence versus promotion of volitional functioning. Developmental Psychology, 43, 633-646.

Su, Y. L., \& Reeve, J. (2011). A meta-analysis of the effectiveness of intervention programs designed to support autonomy. Educational Psychology Review, 23, 159-188. 
Autonomous and Controlled Motivation for Parenting

Table 1 Factor Loadings of the Parenting motivation scale

\begin{tabular}{|c|c|c|}
\hline \multirow[t]{3}{*}{ "I am motivated to take care of my child because..." } & \multirow{3}{*}{$\begin{array}{c}\text { Factor } 1 \\
\text { Controlled } \\
\text { motivation }\end{array}$} & \multirow{3}{*}{$\begin{array}{c}\text { Factor } 2 \\
\text { Autonomous } \\
\text { motivation }\end{array}$} \\
\hline & & \\
\hline & & \\
\hline I want those around me to see me as a good parent. (extrinsic) & .786 & .067 \\
\hline I want to prove to the people around me that I am a good parent. (extrinsic) & .784 & -.015 \\
\hline Others expect me to or the situation demands it. (extrinsic) & .701 & -.130 \\
\hline If I wasn't a good parent, I would feel guilty. (introjected) & .707 & .229 \\
\hline I really want to be a good parent and I would be ashamed if I wasn't. (introjected) & .665 & .237 \\
\hline I feel that I really ought to be a good parent and I would be disappointed in myself if I & .626 & .387 \\
\hline \multicolumn{3}{|l|}{ wasn't. (introjected) } \\
\hline & .057 & .748 \\
\hline \multicolumn{3}{|l|}{ Taking care of my child is important to me and part of my values. (identified) } \\
\hline It is very important to me to do all that I can do to promote the well-being of my child. & .126 & .684 \\
\hline \multicolumn{3}{|l|}{ (identified) } \\
\hline It is important to me that my child has all that he/she needs. (identified) & .240 & .525 \\
\hline Of the enjoyment of learning new things about my child and myself. (intrinsic) & .003 & .696 \\
\hline Of the pleasure and satisfaction that I experience in taking care of my child. (intrinsic) &.-038 & .734 \\
\hline I feel a sense of personal accomplishment in taking care of my teenager in my own & .168 & .659 \\
\hline way. (intrinsic) & & \\
\hline
\end{tabular}


Autonomous and Controlled Motivation for Parenting

Table 2 Partial Correlations of Outcomes with Parenting Motivation

\begin{tabular}{|c|c|c|}
\hline Family Education, $\mathrm{n}=563$ & .09 & -.09 \\
\hline Family Income, $n=563$ & .12 & -.02 \\
\hline Child's Sex ( $1=$ boy, $2=$ girl $), \mathrm{n}=563$ & $.16^{* *}$ & -.06 \\
\hline Child's Age, $\mathrm{n}=563$ & $-.19 * *$ & -.05 \\
\hline Parent's Age, $n=563$ & .07 & -.04 \\
\hline Parent Competence, $\mathrm{n}=563$ & $.28 * *$ & $-.20 * * *$ \\
\hline Parent Satisfaction, $\mathrm{n}=563$ & $.37 * *$ & $-.17 * *$ \\
\hline Infant Temperament, $\mathrm{n}=151$ & -.02 & -.06 \\
\hline Permissive Style, $\mathrm{n}=67$ & -.09 & .16 \\
\hline Authoritative Style, $n=67$ & $.46^{* *}$ & .09 \\
\hline Parent Autonomy Support, $\mathrm{n}=77$ & $24 *$ & -.01 \\
\hline Parent Life Satisfaction, $n=260$ & $.24 *$ & $-.19 *$ \\
\hline Parent Mood, $n=260$ & $.16^{*}$ & $-.26 *$ \\
\hline
\end{tabular}

\footnotetext{
$* \mathrm{p}<.05 ; * * \mathrm{p}<.01$
} 